\title{
Numerical analysis of ice accretion effects at super-cooled large droplet conditions on airfoil aerodynamics
}

\author{
Chengxue $\mathrm{LIU}^{1 *}$, Yongzhong WANG ${ }^{2}$ \\ 1. Xinjiang Air Traffic Management Bureau, Urumqi 830016, China \\ 2. College of Air Traffic Management, Civil Aviation Flight University of China, Guanghan 618307, China
}

\begin{abstract}
Changes in flow field around NACA23012 airfoil from a clean condition to a super-cooled large droplet (SLD) condition were simulated, and variations in aerodynamic parameters were calculated using FLUENT. In the case of numerical simulation for a clean airfoil, flow field characteristics simulated agreed well with theory analysis, indicating that turbulence models and parameters setting are feasible. Aerodynamic parameters for iced airfoil were calculated using the same method and agreed with those measured test data under the same environment in icing wind tunnels by S. Lee. Conclusion is made that the numerical simulation is valid, and it can be an alternative to study ice accretion effects at the SLD condition on airfoil aerodynamics, leading to reduction in research cycle time and cost.
\end{abstract}

Key words: super-cooled large droplet; wings ice accretion; numerical simulation; aerodynamics; FLUENT

(C) 2011 JMT. All rights reserved.

\section{Introduction}

$\mathrm{I}$ ce accretion on aircraft wings is a hazard to flight safety. It will reduce lift and angle of attack, increase drag, and cause degradation in stability and operation.

SLDs refer to super-cooled large droplets whose diameters are larger than 40 micrometers. SLDs are larger than cloud droplets and usually exist in freezing rain. Clear ice formed by SLDs has adverse effects on flight [1]. The ATR-72 crash occurred in Roselawn, Indiana in 1994 was reported to be caused by ridge ice formed behind the leading edge deicing system [2]. Johnson [3] found that ridge ice formed aft of the deicing system resulting in a larger lift loss and drag increase than when the leading edge was completely iced over. Therefore, ice formed in the SLD conditions is most hazardous to aircraft aerodynamics. To investigate aircraft icing, there are mainly three ways, namely, flight tests, icing wind tunnel tests, and numerical simulation. Lynch et al. [4] and Bragg et al. [5] reviewed the three research methods, and studied the effects of ice type on flow field around wings and performance degradation caused by ice. Compared with tunnel tests, numerical simulation is an economical and feasible alternative. Levinson et al. [6] discussed concepts with regard to current and future

Received Jun. 16, 2011; revision accepted Nov. 14, 2011 *Corresponding author. E-mail: liushibosuccess@126.com (C.X. LIU)

(C) 2011 JMT. All rights reserved doi: 10.3969/j.issn.2095-087X.2011.04.009 efforts of an icing simulation code, the LEWICE code. Verdin [7] developed a multi-stepping procedure, and adapted it to the new three dimensional icing code ICECREMO2. Habash and his team [8-9] have been devoted to the application of FENSAP-ICE, a complete 3D standalone in-flight icing simulation system. In this paper, we use software FLUENT to analyze effects of ice accretion formed under SLD conditions on airfoil aerodynamics.

\section{Airfoil, ice, and icing cloud conditions}

A two dimensional NACA23012 airfoil with 18-inch chord was used in the simulation process. It is generally believed that ice formed under the SLD conditions is ridge ice, which has various shapes, but all has protuberance geometry. For the convenience of simulation, we adopt a quarter-round ice shape. Icing conditions in flight are as follows: air velocity $v=0.13 \mathrm{Mach}$, ambient air temperature $T=-15^{\circ} \mathrm{C}$, air pressure $P=1013.25 \mathrm{hPa}$, and Reynolds number $R=1.8 \times 10^{6}$.

\section{Computational methods}

\subsection{Calculation for clean airfoil}

\subsubsection{Drawing of NACA23012 airfoil}

According to airfoil database at University of Illinois at Urbana-Champaign [10], scatter diagram of NACA23012 
airfoil was drawn using Gambit as shown in Fig. 1. The total number of points in the scatter diagram is 68 . The leading edge of the flap is located at $0.75 c$ ( $c$ is chord length of the airfoil), and flap length is $0.25 c$.

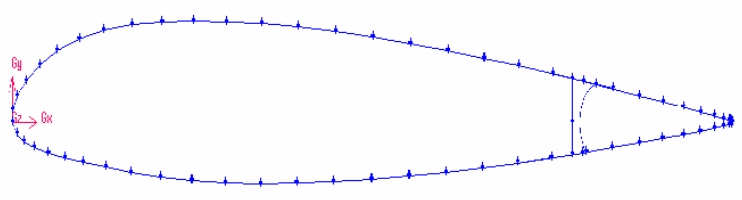

Fig. 1 NACA23012 wing section

\subsubsection{Grid generation}

In order to obtain accurate lift, drag, and pitching moment on airfoil, grids near the airfoil must be dense enough and computed fields must be large enough to satisfy farfield boundary conditions. However, excessive fields and grids will cost too much computing resources and slow computing speed. Thus, the compromise is that grids near the airfoil are dense, and grids far from the airfoil are scattered.

Computed fields are shown in Fig. 2, where $L$ and $T$ are leading and trailing edges of the airfoil. Left part is a half circle with a center at $T$, and a radius of $12.5 \mathrm{c}$. Right part are two rectangles, where $A B=E D=T C=20 c$, and $A T=T E=12.5 c$.

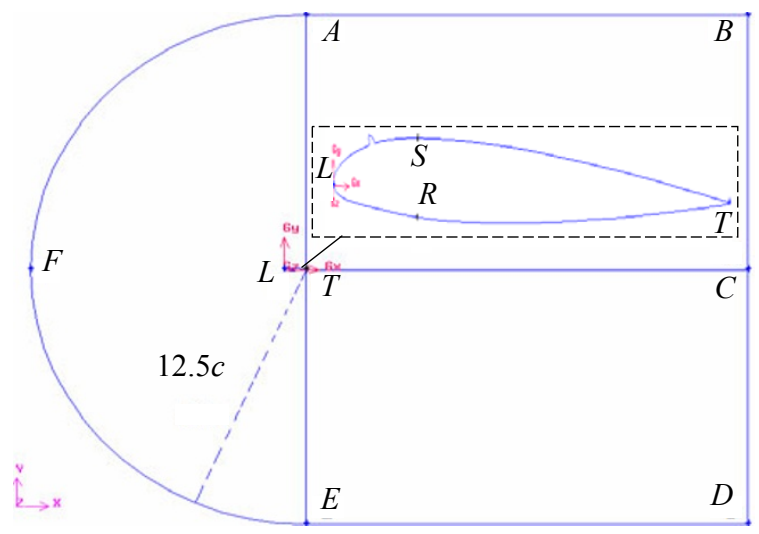

Fig. 2 Computed flow field for NACA23012 airfoil

The upper and lower surfaces of the wing are divided into four arcs: $L S, S T, L R$, and $R T$. These four arcs are meshed in Gambit, and grids on arc $L S$, due to ridge ice, are more dense than others. At last, grids for three areas in Fig. 2 are generated successively as shown in Fig. 3.

Fig. 3(a) shows all grids in computed fields. By performing the command "Grid Check" in FLUENT, we know that the total number of grids is 12150 , the volume of the smallest grid $2.375483 \times 10^{-5} \mathrm{~m}^{3}$, and the volume of the largest grid $2.304004 \times 10^{-1} \mathrm{~m}^{3}$. Fig. 3(b) shows the grids surrounding the airfoil.

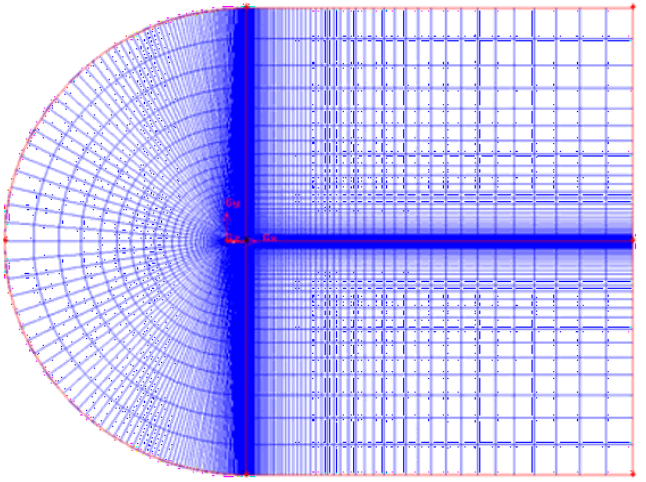

(a) Grids in computed fields for clean NACA23012 airfoil

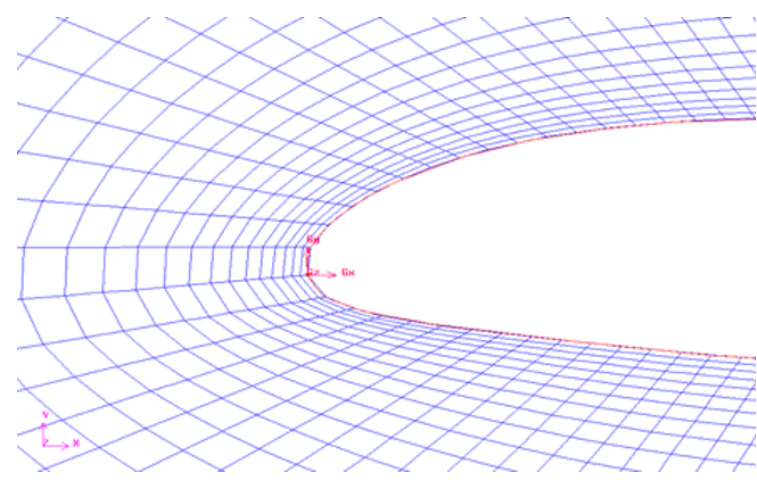

(b) Grids surrounding the clean NACA23012 airfoil

Fig. 3 Grids for NACA23012 airfoil

\subsubsection{Calculation using FLUENT}

Boundary of the airfoil is set as wall boundary. Edges in Fig. 2 (i.e., arc $A F E$, and edges $A B, B C, C D$ and $D E$ ) are far field pressure boundary. The medium is assumed to be ideal gas. It was found by Mortensen [11] and Zhou [12] that in the simulation of flow field around a wing airfoil, Spalart-Allmaras model is more accurate than RNG $k-\varepsilon$, Standard $k-\varepsilon$, and realizable $k-\varepsilon$ model. To save time consumption, Spalart-Allmaras model [13] is chosen. A coupled pressure based algorithm is used. Standard difference scheme is applied for pressure term, and second-order upwind scheme for momentum term, turbulence kinetic energy term and turbulence kinetic energy dissipation term. Iteration accuracy is 0.001 .

Contour of static pressure at $\alpha=5^{\circ}$ is shown in Fig. 4. As NACA23012 has an asymmetrical wing and angle of attack is positive, flow tube becomes thinner when air flows pass the upper surface of the airfoil. In conformity with the continuity theorem and Bernoulli's theorem, flow velocity increases and kinetic pressure falls in this situation. Thus, static pressure becomes larger.

In general, two streamlines in one flow field will not intersect simultaneously, but there are exceptions: the areas with zero flow rate and infinite flow rate. Inter- 
secting of streamlines near wall surfaces in Fig. 5 shows that flow rate near wall surfaces is 0 . Fig. 5 shows that the velocity of air flow near the upper surface of the airfoil becomes larger, and that near the lower surface becomes smaller.

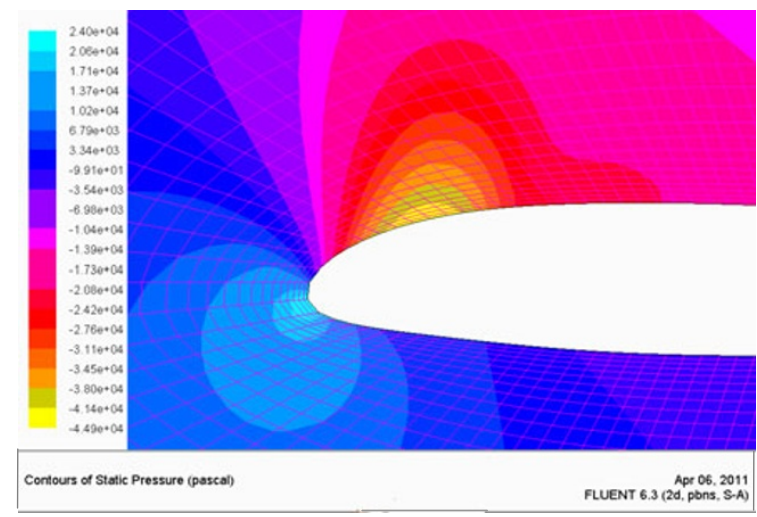

Fig. 4 Contour of static pressure around clean NACA23012 airfoil at $\alpha=5^{\circ}$

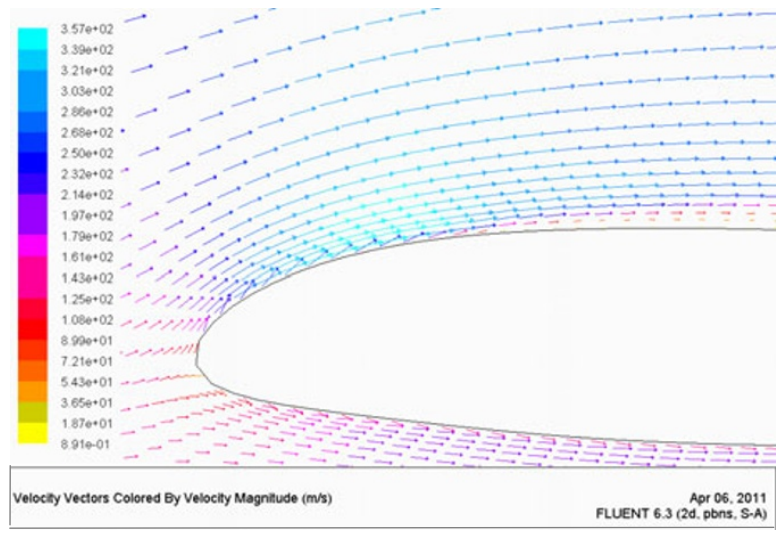

Fig. 5 Contour of velocity vectors around clean NACA23012 airfoil at $\alpha=5^{\circ}$

\subsection{Calculation for iced airfoil and results verification}

The ice is quarter round with a radius of $h$, and lateral coordinate of the airfoil chord is denoted as $x$.

\subsubsection{Drawing of ice on the airfoil}

Ice height $h$ is equal to $0.0762 \mathrm{~m}$, and the ice is located at $x / c=0.1$ on the upper surface of the airfoil. The combination of ice and airfoil by Gambit is shown in Fig. 6 .

\subsubsection{Grid generation}

Computed field of iced airfoil is the same as that of clean airfoil. First edges near quarter-round ice are meshed densely, and then the half circle area is meshed, followed by the grid generation of the two rectangles.
The total number of grids is 63836 , the volume of the smallest grid is $5.941388 \times 10^{-7} \mathrm{~m}^{3}$, and the volume of the largest grid is $1.083809 \mathrm{~m}^{3}$. Fig. 7 depicts grids near the junction of ice and the airfoil.

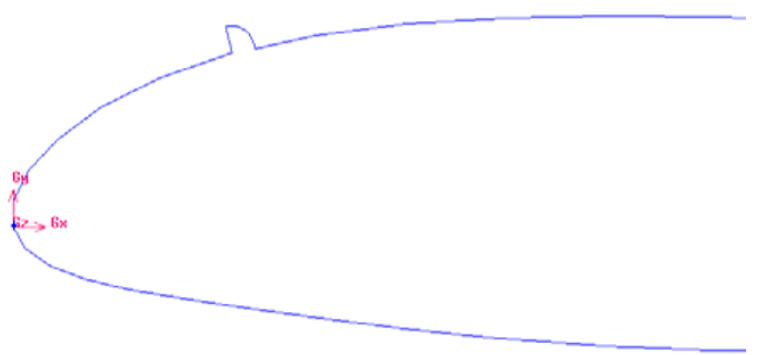

Fig. 6 Quarter-round ice on NACA23012 airfoil

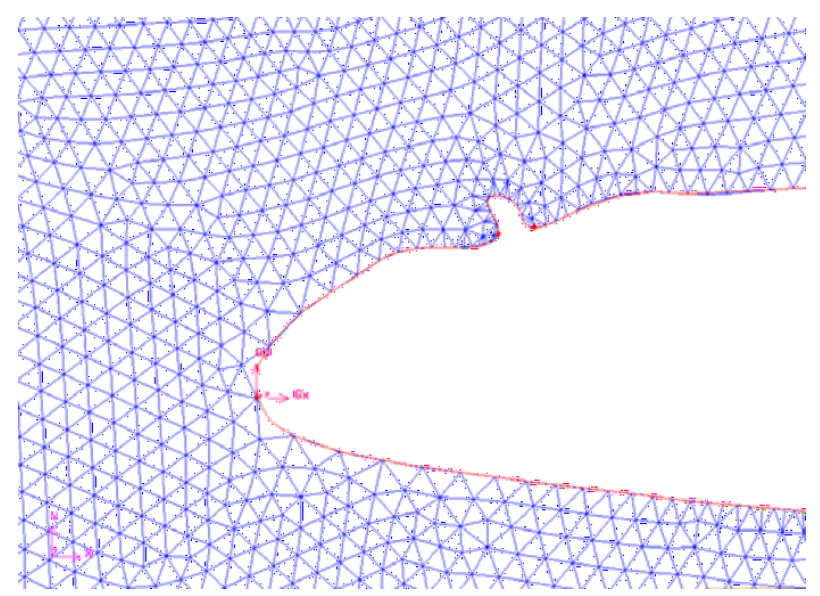

Fig. 7 Grids around iced NACA23012 airfoil

\subsubsection{Solution by FLUENT}

Spalart-Allmaras turbulence model is chosen, and the other parameters are also the same as those of clean airfoil. Lift coefficient, drag coefficient, and pitching moment are monitored parameters. The function of lift coefficient, drag coefficient and pitching moment versus iteration times are obtained. The solution converges after 1400 iteration times. Fig. 8 shows the function of drag coefficient versus iteration times.

Contour of static pressure around the iced airfoil is shown in Fig. 9. By comparing it with Fig. 4, we know that the ice on the upper surface of the airfoil decreases the pressure at the rear area of the airfoil upper surface. Thus, the suction force on the upper surface of the airfoil will decrease and so will the lift on the whole airfoil. This will be verified in the calculation of lift coefficient later.

Velocity vectors around the iced airfoil are shown in Fig. 10. By comparing it with Fig. 5, we know that ice on the upper surface of the airfoil disturbs air flow along 
the upper surface, and leads to nonuniform distribution of air velocity near upper surface of the airfoil. It further disturbs air flow near the back of the airfoil, causing nonuniform distribution of air velocity in the boundary layer, the pulsating of pressure field outer boundary layer, and eventually separating air flow in advance.

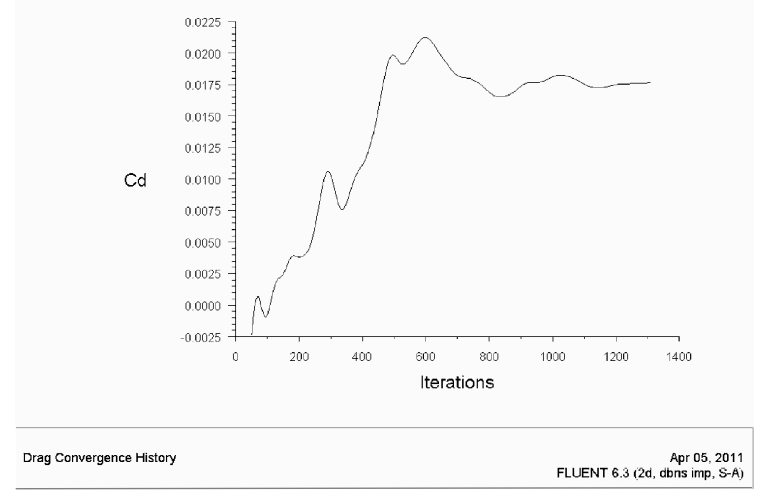

Fig. 8 Function curve of drag coefficient versus iteration times

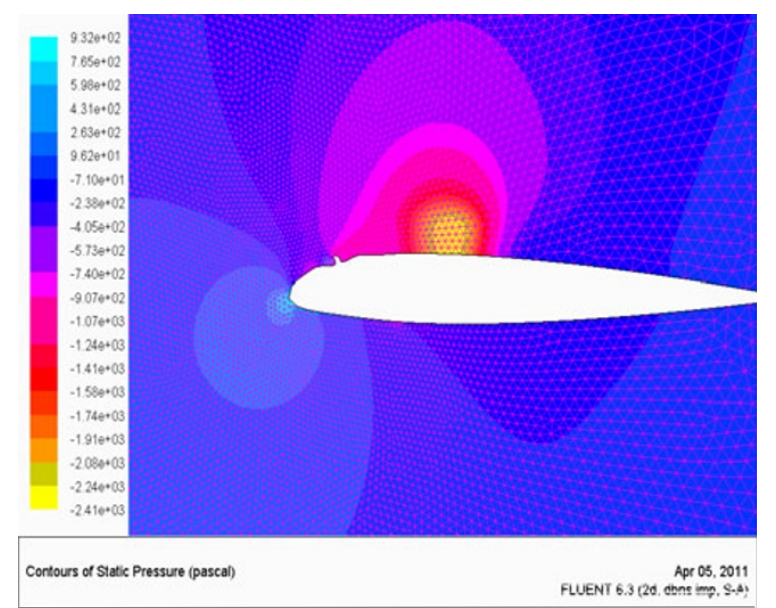

Fig. 9 Contour of static pressure around iced NACA23012 airfoil at $\alpha=5^{\circ}$

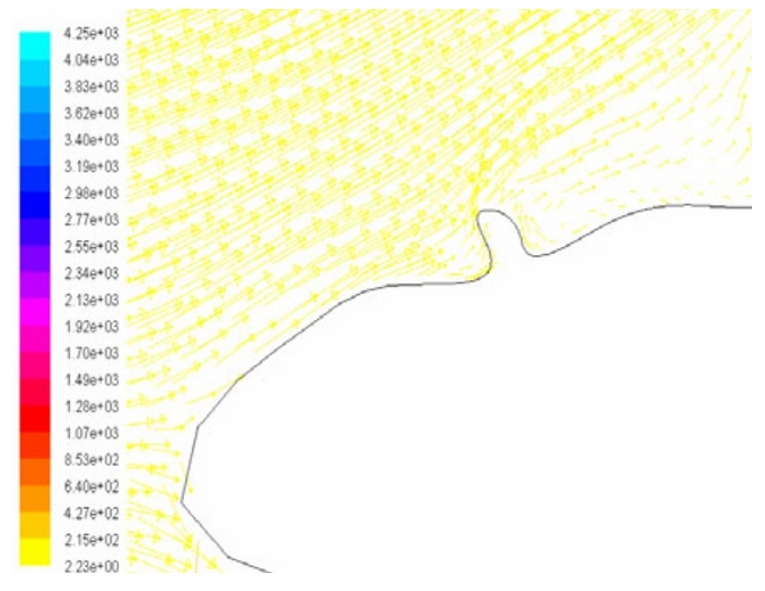

Fig. 10 Contour of velocity vectors around iced NACA23012 airfoil at $\alpha=5^{\circ}$

\subsubsection{Verification and analysis of aerodynamic parameters}

Using the same calculation procedure, we calculate the aerodynamic parameters when the angle of attack varies between $-5^{\circ}$ and $20^{\circ}$. Then we will compare them with S. Lee's results obtained in icing wind tunnels [14].

(a) Lift coefficient. Lift coefficient variations are shown in Fig. 11. When angle of attack is larger than $2^{\circ}$, lift coefficient loss of the iced airfoil is significant. The maximum lift coefficient of clean airfoil is 1.5 when $\alpha=15^{\circ}$, and the maximum lift coefficient of iced airfoil is 0.25 when $\alpha=3^{\circ}$. When $\alpha>3^{\circ}$, the lift coefficient of iced airfoil nearly keeps unchanged.

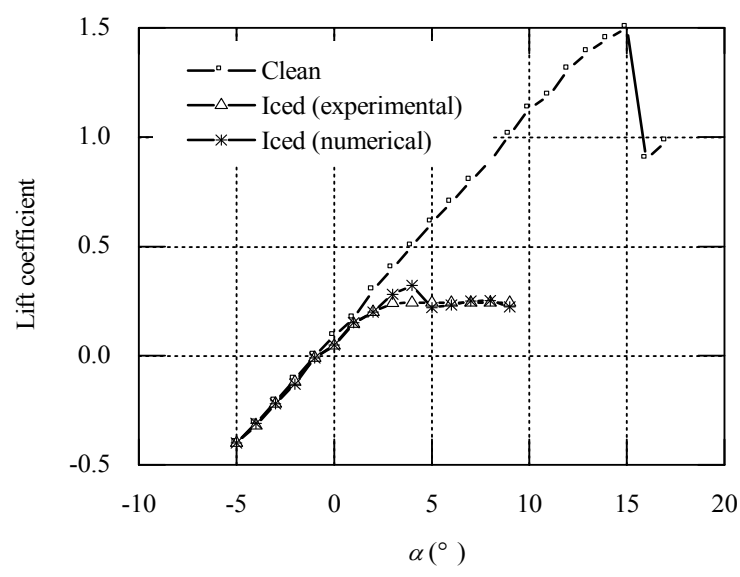

Fig. 11 Lift curves for clean and iced airfoils

(b) Lift-drag ratio. We use FLUENT to calculate the drag coefficient of the airfoil at different angles of attack, as shown in Fig. 12. It is seen that the lift-drag ratio for iced airfoil is smaller than that of clean airfoil. This is partly because the drag coefficient for iced airfoil is larger than that of clean airfoil when lift coefficients for iced and clean airfoil are equal. Note that the quarter-round ice leads to air flow separation in advance along the upper surface of the airfoil, which increases pressure drag on the airfoil.

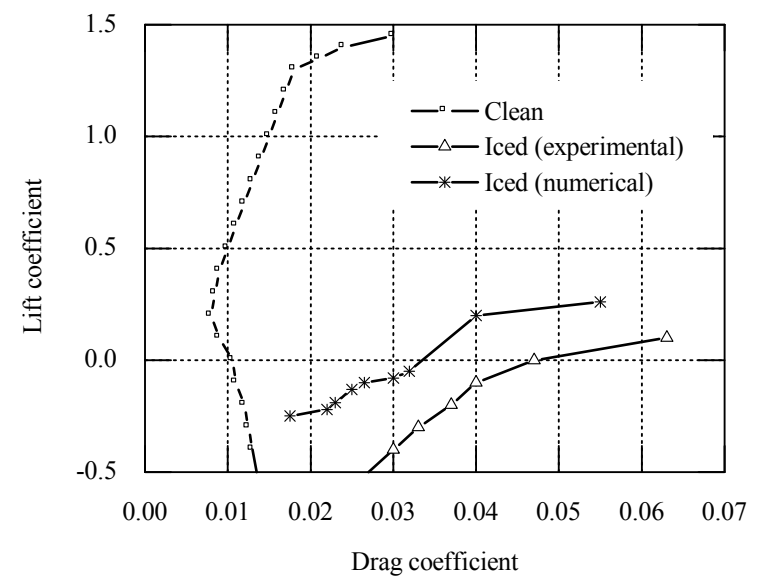

Fig. 12 Polar curves for clean and iced airfoils 
In addition, the quarter-round ice enhances roughness of airfoil surface, and increases the friction drag of the airfoil. This contributes to increasing drag coefficient.

(c) Pitching moment coefficient. Pitching moment coefficients for clean and iced airfoils are shown in Fig. 13. Compared with the clean airfoil, pitching stability of the iced airfoil worsens.

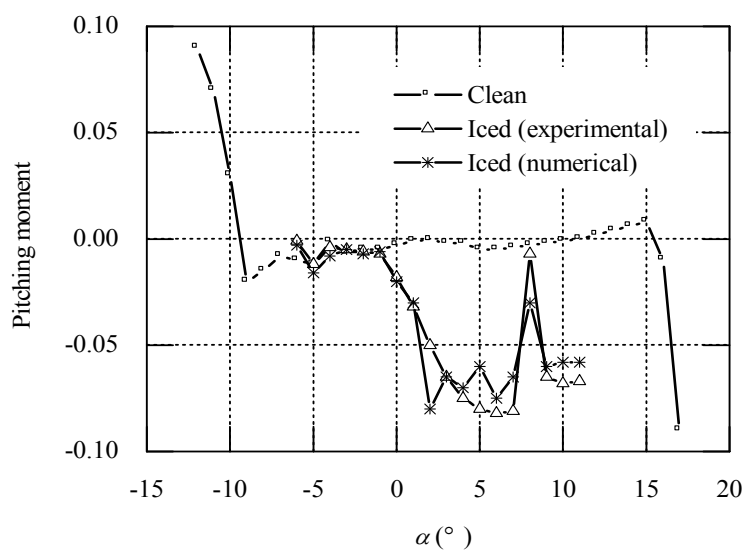

Fig. 13 Pitching moment for clean and iced airfoils

\section{Error analysis}

From Figs. 11 to 13 , it can be seen that aerodynamic parameters calculated by FLUENT agree well with the experiments on the whole though lift coefficient calculated is a little larger, and pitching moment coefficient calculated is more stable. These deviations may be attributed to the following reasons.

(a) Effects of turbulence models. There are mainly two fluid flows, i.e., laminar flow and turbulence flow. Generally speaking, turbulence flow is usual and laminar flow is few. Although turbulence theory is developing rapidly, there are still intrinsic differences between results obtained from numerical simulation and those of experiments.

(b) Grid generation and discretion of control equations. The higher the grid resolution is, the more accurate calculation results are.

(c) Deformation at junction of the ice and airfoil. As Fig. 7 shows, the shape of wall boundary has changed after meshing, and the flow field around it has changed as well. This shape change is insignificant in view of ice height, and it can not cause large change to flow field around the airfoil.

\section{Conclusions}

(a) Aerodynamic parameters calculated by FLUENT fit well with experiments, which demonstrates that the method used in numerical simulation is feasible, and it can work as a substitute for tunnel test in studying SLD ice accretion effects on airfoil aerodynamics.

(b) The quarter-round ice disturbs air flow along the upper surface of the airfoil, leads to air flow separation in advance, further decreases lift, and increases drag and worsens pitch stability. When the angle of attack is $5^{\circ}$, lift coefficient decreases by $63.93 \%$, and drag coefficient increases by $263.63 \%$.

\section{Acknowledgements}

This research was supported by the Fund of the CAAC Scientific Research Base of Civil Aviation Flight Technology and Safety (No. F2010KF02).

\section{References}

[1] Federal Aviation Administration, Aircraft Icing Handbook, New Zealand: Safety Education and Publishing Unit, 2001.

[2] National Transportation Safety Board, Aircraft Accident Report: Uncontrolled Collision With Terrain Flagship Airlines, Inc., dba American Eagle Flight 5379, Bae Jetstream 2201, N918AE Morrisville, North Carolina, Washington D.C.: National Transportation Safety Board, 1995.

[3] S. Lee, Effects of Super-cooled Large-droplet Icing on Airfoil Aerodynamics [Dissertation], Illinois: University of Illinois, 2001.

[4] F.T. Lyncha, A. Khodadoust, Effects of ice accretions on aircraft aerodynamics, Progress in Aerospace Sciences, 2001, 37(1): 669-767.

[5] M.B. Bragg, A.P. Broeren, L.A. Blumenthal, Iced-airfoil aerodynamics, Progress in Aerospace Sciences, 2005, 41(1): 323-362.

[6] L.H. Levinson, M.G. Potapczuk, P.A. Mellor, Software Development Processes Applied to Computational Icing Simulation, Cleveland: NASA Glenn Research Center, 1999.

[7] P. Verdin, An Automatic Multi-stepping Approach for Aircraft Ice Prediction [Dissertation], Cranfield: Cranfield University, 2007.

[8] W.G. Habash, M. Aube, G. Barruzzi, et al., FENSAP- ICE: a fully-3d in-flight icing simulation system for aircraft, rotorcraft and UAVS, In: Proc. of 24th International Congress of the Aeronautical Sciences, Yokohama, 2004.

[9] H. Beaugendre, F. Morency, W.G. Habashi, FENSAPICE: roughness effects on ice shape prediction, AIAA Paper, 2003.

[10] UIUC airfoil coordinates database, http://www.ae.illinois. edu/m-selig/ads/coord_database, 2011-04-01.

[11] K. Mortensen, CFD Simulations of an Airfoil with Leading Edge Ice Accretion [Dissertation], Copenhagen: Technical University of Denmark, 2008.

[12] H. Zhou, S.L. Hu, Numerical analysis of the aerodynamic performance of an airfoil with round Ice, Chinese Quarterly of Mechanics, 2006, 28(1): 28-33 (in Chinese).

[13] FLUENT 6.3 help, http://www.ansys.com, 2011-04-01.

[14] S. Lee, M.B. Bragg, Investigation of factors affecting iced-airfoil aerodynamics, Journal of Aircraft, 2003, 40(3): 499-508. 